\title{
Breaking a Guinness World Record on Hand Sanitizing Relay, initiating a call for vital research in overcoming campaign
} fatigue for hand hygiene [version 1; peer review: 2 approved, 1 approved with reservations]

\author{
Wing Hong Seto ${ }^{1}$, Kwok-Hung Li ${ }^{1}$, Christina Woon Yee Cheung ${ }^{2}$, \\ Patricia Tai Yin Ching2, Benjamin J. Cowling ${ }^{3}$ \\ ${ }^{1}$ Department of Pathology, Hong Kong Baptist Hospital, Kowloon Tong, Hong Kong \\ 2Infection Control Unit, Hong Kong Baptist Hospital, Kowloon Tong, Hong Kong \\ ${ }^{3}$ School of Public Health, The University of Hong Kong, Pokfulam, Hong Kong
}

V1 First published: 03 Oct 2014, 3:234

https://doi.org/10.12688/f1000research.5403.1

Latest published: 16 Feb 2015, 3:234

https://doi.org/10.12688/f1000research.5403.2

\section{Abstract}

Hand hygiene has been shown to be effective in significantly reducing hospital acquired infections for many years. However it is difficult to maintain and enhance compliance with hand hygiene guidelines. In Hong Kong, we previously reported a strategy to counter campaign fatigue from $50 \%-55 \%$ in $2009-11$ to $83 \%$ in 2012 . Here we report a creative activity that we used to sustain and enhance hand hygiene compliance. In May 2014 we broke the first Guinness World Record for a Hand Sanitizing Relay. A total of 277 participants performed hand hygiene before two official and approved witnesses. Following this team-directed strategy, an increase in hand hygiene compliance was identified in two clinical areas with previously poor compliance. The longer term impact of this strategy remains to be determined. More broadly, further research is urgently needed on meeting the challenge of campaign fatigue, and maintaining and enhancing compliance with hand hygiene guidelines.

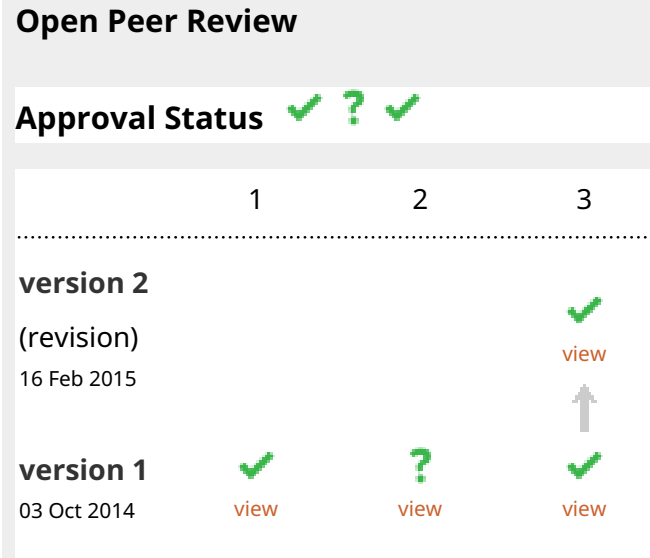

1. Mary-Louise McLaws, University of New South Wales, Sydney, Australia

2. Vicki Erasmus, Erasmus MC University Medical Center Rotterdam, Rotterdam, The Netherlands

3. Alison Holmes, Imperial College London, London, UK

Any reports and responses or comments on the article can be found at the end of the article. 
Corresponding author: Benjamin J. Cowling (bcowling@hku.hk)

Competing interests: No competing interests were disclosed.

Grant information: The author(s) declared that no grants were involved in supporting this work.

Copyright: @ 2014 Seto WH et al. This is an open access article distributed under the terms of the Creative Commons Attribution License, which permits unrestricted use, distribution, and reproduction in any medium, provided the original work is properly cited. Data associated with the article are available under the terms of the Creative Commons Zero "No rights reserved" data waiver (CC0 1.0 Public domain dedication).

How to cite this article: Seto WH, Li KH, Cheung CWY et al. Breaking a Guinness World Record on Hand Sanitizing Relay, initiating a call for vital research in overcoming campaign fatigue for hand hygiene [version 1; peer review: 2 approved, 1 approved with reservations] F1000Research 2014, 3:234 https://doi.org/10.12688/f1000research.5403.1

First published: 03 Oct 2014, 3:234 https://doi.org/10.12688/f1000research.5403.1 


\section{Introduction}

Hand hygiene (HH) has been shown to be effective in significantly reducing hospital acquired infections for many years ${ }^{1}$. To ensure that this is practiced all over the world, the World Health Organization (WHO) launched the First Patient Safety Challenge in $2005^{2}$. This is highly successful and as of 24 September 2014 a total of 134 member states of WHO have pledged their support ${ }^{3}$. The WHO has also provided guidelines on $\mathrm{HH}$ with full details on the proper procedures and also guidance on the proper implementation strategy ${ }^{4}$.

Although the effects of $\mathrm{HH}$ are firmly established, it is not easy to achieve compliance to the $\mathrm{HH}$ guideline. This is because all staff in the hospital must practice it consistently before, during and after contact with patients and their immediate surroundings. Fully recognizing that compliance is difficult, the WHO guideline has laid out a clear strategy for implementation which includes five essential steps:

Step 1: Facility preparedness including resources and formulating a plan

Step 2: Baseline evaluation - establishing the current situation

Step 3: Implementation - introducing the improvement activities

Step 4: Follow-up evaluation - evaluating the implementation impact

Step 5: Further planning and review cycle.

It should be noted that the WHO also recommends that a plan be developed for the review cycle that is ongoing for a minimum of five years.

The WHO has formulated a Multimodal Hand Hygiene Improvement Strategy (MHHIS) for promoting the HH practice. This strategy is not limited to a single promotional component such a posters and banners. Rather the WHO endorses a myriad of coordinated actions including system change to ensure that alcohol-based handrub and handwashing facilities are in place, continuous training and education programs, $\mathrm{HH}$ audits with feedback, reminders in the workplace, and fostering institutional safety climate in the hospital.

\section{Systematic reviews on efficacy of $\mathrm{HH}$ campaigns}

Three reviews on $\mathrm{HH}$ compliance have been reported in the literature. One review was conducted before 2010 which included all studies in English from a market economy with proper description of results ${ }^{5}$. A total of 96 studies were included and the results were rather variable but the authors concluded that noncompliance with hand hygiene guidelines is a universal problem and that this can be present even when all the basic requirements for implementation as recommended above were in place. It is stressed that to develop successful interventions, more research on behavioral determinants is needed. The second is a Cochrane review with updates searches up till November 2009 and was published in 2011 ${ }^{6}$. The standards for selection were much more stringent and only studies with controls or interrupted time series with explicit entry and quality criteria were considered and finally only four studies were included. Two studies had data on $\mathrm{HH}$ compliance and only one showed improvement from the campaign. The other two reported improvement based in increase in usage of hand disinfectants. The authors of the review concluded that soundly designed studies are still required with at least 12 months of follow up. This is because the short duration of the included studies did not permit assessment of the long term impact of the campaigns.

Another review by Huis et al. reported in 2012 was conducted but with a focus on classifying the improvement activities based on their determinants of behavior change ${ }^{7}$. It was stated in the review that the criteria for inclusion were not as stringent as Gould et al. ${ }^{6}$ but rather the standards of Anderson and Sharpe were used ${ }^{8}$. Nevertheless the papers included must have clearly described their intervention methods for these to be evaluated and finally 41 studies were included. The review concluded that the strategies are rather limited and "we should be more creative in the application of alternative activities". The authors encouraged further research particularly on group-directed and team-directed strategies in addition to strategies focusing on the individual or organization.

\section{Recent studies on the long term impact of $\mathrm{HH}$ campaigns}

As stated in the review by Erasmus et al. ${ }^{5}$, there is a lack of data showing the long term impact of $\mathrm{HH}$ campaigns. There are however two studies published in 2014 with data on the impact beyond two years. The first by Myer et al. ${ }^{9}$ reported a significant increase of $\mathrm{HH}$ compliance from $22 \%-40 \%$ in 2000 to $65 \%-81 \%$ in $2003-$ 2006. Data for compliance of the different categories of healthcare workers from 2003 to 2006 were also provided and there were no increases recorded during these three years. The compliance data in 2003 and 2006 were the following: physicians (63\%; 60\%), Nurses $(72 \% ; 75 \%)$ and other ancillary $(65 \% ; 63 \%)$. In another study, Biswal et al. reported an increase in $\mathrm{HH}$ compliance from $28 \%$ to $43 \%$ after six months ${ }^{10}$. However an audit conducted two years later shows that compliance had fallen to $36 \%$. These two studies indicate that it is not easy to further enhance compliance in the long term.

\section{Meeting the challenge of campaign fatigue}

The WHO guidelines can be extremely helpful but with the passage of time, maintaining compliance can indeed be problematic. We were the first to report a paper on campaign fatigue in $\mathrm{HH}$, in a hospital in which all components of the WHO MHHIS were utilized $^{11}$. The compliance to HH successfully increased from $41 \%$ to $58 \%$ in 2008 . However in spite of adding the various components of the MHHIS as recommended, compliance remained at $53 \%$ in 2009, 55\% in 2010 and 50\% in 2011. Compliance that remains static despite active promotional activities is evidence of campaign fatigue. This is similar to advertisement fatigue, defined as the lack of effects on users resulting from frequent and repeated exposures ${ }^{12}$.

We reported a technique to overcome campaign fatigue utilizing the help of frontline link nurses ${ }^{11}$. This was successful in bringing the HH compliance rate from $50 \%$ to $83 \%$ in 2012 . The improvement was noted in all the 19 clinical areas except for two where together there was a decline in compliance from $42 \%$ to $10 \%$.

As recommended by Huis et al. ${ }^{7}$ it is important to explore creative alternative activities to promote $\mathrm{HH}$ especially for a program 
that is ongoing for an extended period. Breaking a world record is an exciting endeavor and perhaps this can be one way to meet the challenge but it must be formatted in a manner that will enhance compliance with $\mathrm{HH}$. Breaking the world record for $\mathrm{HH}$ had been done before but the record was to be the largest group of participants to do hand washing. It was first started in Bangladesh in 2008, and the latest record was organized by WHO Pan American Health Organization with a total of 740,870 participants in $2011^{13}$. In this world record, the emphasis was on the total number of participants and not on the proper hand hygiene technique and thus there was no attempt to demonstrate any increase in compliance.
In the recent breaking of the first Hand Sanitizing Relay in May 2014, the concept is different. Every individual participant must perform $\mathrm{HH}$ before two official and approved witnesses who timed each person using a stopwatch, and recorded by video as required (Figure 1). It is done in a relay and the participant must perform $\mathrm{HH}$ correctly before passing on the alcohol hand rub to the next person (Figure 2). The entire process was validated by Guinness World Records. In the breaking of this record, a total of 277 participants were involved in the relay (Figure 3). What is pertinent is that the compliance of the two clinical areas showing a decline in compliance mentioned above increased to $95 \%$ in June 2014. It seems that

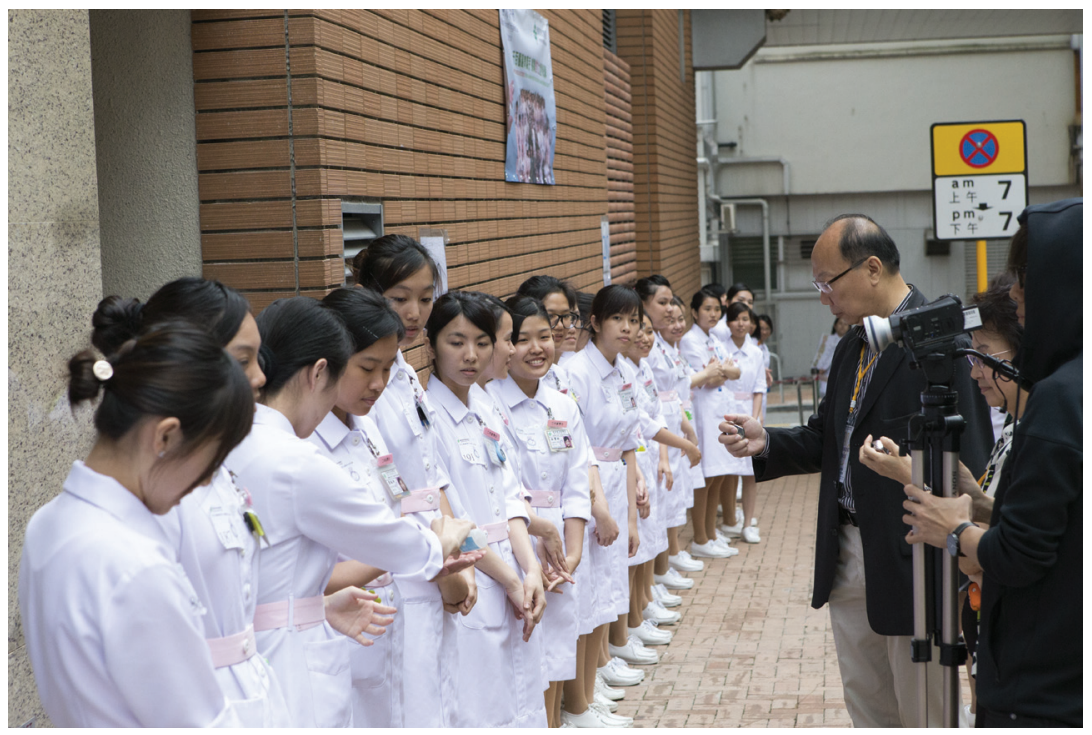

Figure 1. Row of nurses in the relay before the two official validating witnesses, with their stop-watches and the video camera recording each individual performance in the relay.

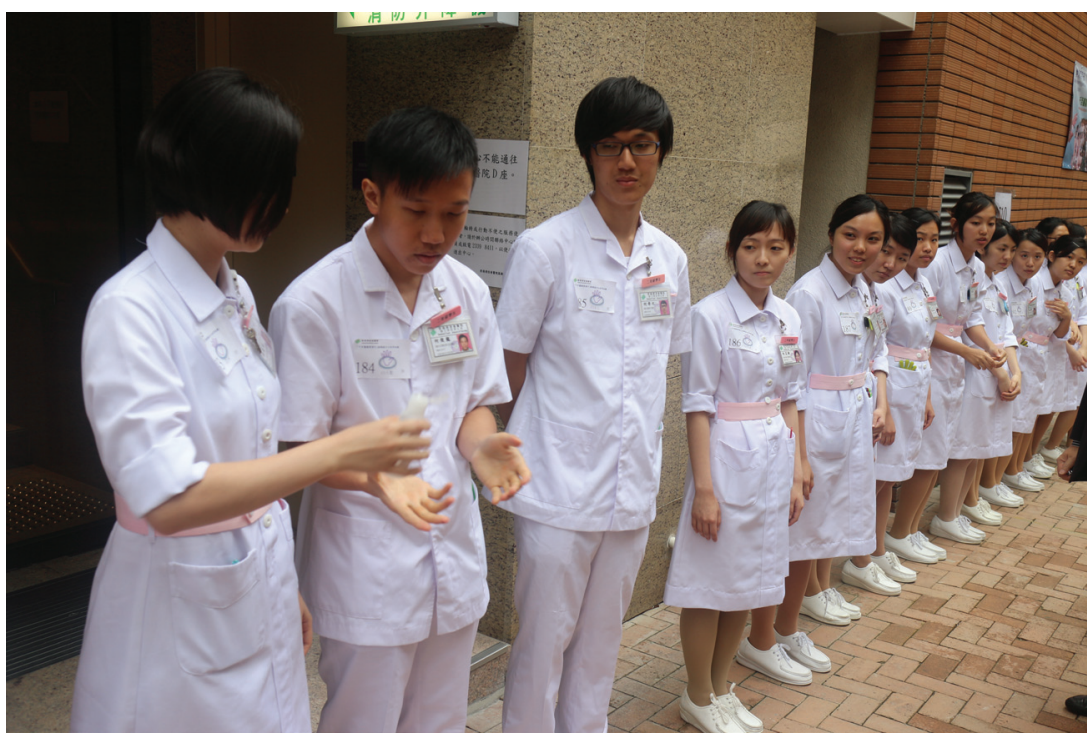

Figure 2. Row of nurses in the relay, the first nurse has just performed hand hygiene correctly and is pouring the alcohol hand rub for the next person. 


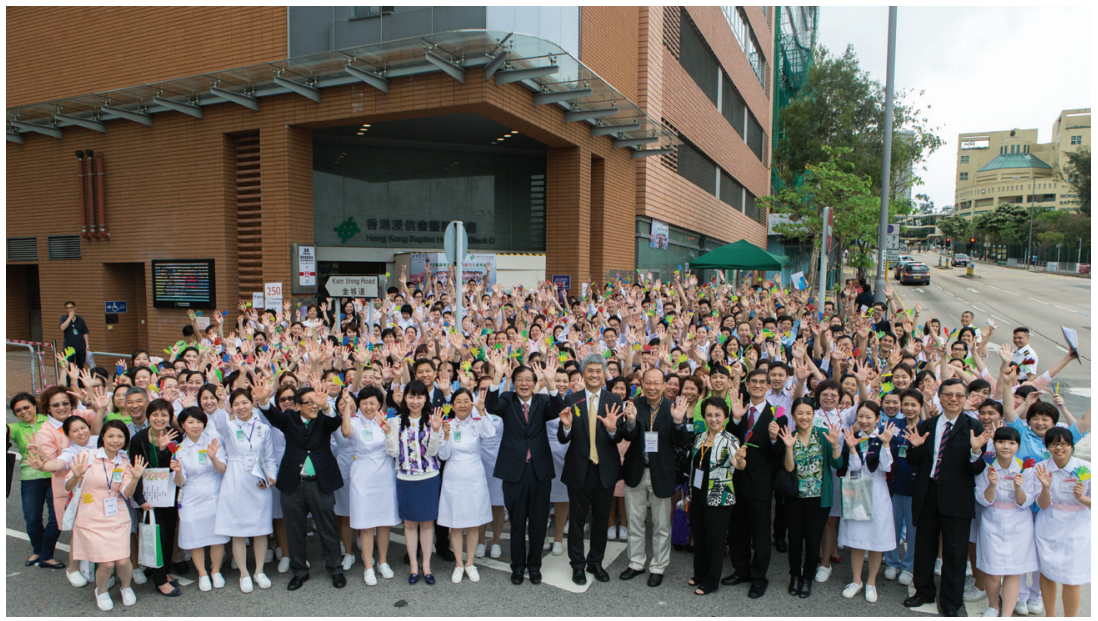

Figure 3. Celebratory photograph after completion of the Hand Sanitizing Relay world record at Hong Kong Baptist Hospital.

not all health care workers will respond similarly to a promotional campaign and other high impact activities are needed to enthuse the relatively slow movers. Furthermore, Huis et al. ${ }^{7}$ also stressed the need for team-directed strategies and the relay format in this record fits this criterion precisely.

In conclusion, the essential point to stress in this report is that for health promotional campaigns that are ongoing, it is important to have further research on meeting the challenge of campaign fatigue. This is especially relevant because the HH campaign of WHO is approaching its ten year anniversary and campaign fatigue must certainly be emerging all over the world. Presently the data on this vital subject is meager and indeed more work is needed. The hospital is recognized as one of the most complex organizations in existence. Understanding campaign fatigue is essential not only for $\mathrm{HH}$ but also for in the promotion of appropriate healthcare in general.

\section{Author contributions}

All authors declare that they have participated in the conception, design, analysis and writing of the manuscript and have read and approved the final version.

\section{Competing interests}

No competing interests were disclosed.

\section{Grant information}

The author(s) declared that no grants were involved in supporting this work.
1. Pittet D, Hugonnet S, Harbarth S, et al.: Effectiveness of a hospital-wide programme to improve compliance with hand hygiene. Infection Control Programme. Lancet. 2000; 356(9238): 1307-1312. PubMed Abstract | Publisher Full Text

2. Pittet $D$, Donaldson L: Clean Care is Safer Care: a worldwide priority. Lancet. 2005; 366(9493): 1246-1247.

PubMed Abstract | Publisher Full Text

3. World Health Organization. Clean care is safer care. Reference Source

4. World Health Organization. WHO guidelines on hand hygiene in health care Geneva: Switzerland, 2009.

Reference Source

5. Erasmus V, Daha TJ, Brug H, et al:: Systematic review of studies on compliance with hand hygiene guidelines in hospital care. Infect Control Hosp Epidemiol. 2010; 31(3): 283-294

PubMed Abstract | Publisher Full Text

6. Gould DJ, Moralejo D, Drey N, et al.: Interventions to improve hand hygiene compliance in patient care. Cochrane Database Syst Rev. 2010; (9): Art. No. CD005186.

PubMed Abstract | Publisher Full Text

7. Huis A, Van Achterberg T, de Bruin M, et al:: A systematic review of hand hygiene improvement strategies: a behavioural approach. Implement Sci. 2012; 7: 92. PubMed Abstract | Publisher Full Text | Free Full Text
8. Anderson LA, Sharpe PA: Improving patient and provider communication: A synthesis and review of communication interventions. Patient Educ Couns. 1991; 17(2): 99-134 Publisher Full Text

9. Mayer J, Mooney B, Gundlapalli A, et al.: Dissemination and sustainability of a hospital-wide hand hygiene program emphasizing positive reinforcement. Infect Control Hosp Epidemiol. 2011; 32(1): 59-66. PubMed Abstract | Publisher Full Text

10. Biswal M, Rajpoot S, Dhaliwal N, et al.: Evaluation of the short-term and longterm effect of a short series of hand hygiene campaigns on improving adherence in a tertiary care hospital in India. Am J Infect Control. 2014; 42(9): 1009-10. PubMed Abstract | Publisher Full Text

11. Seto WH, Yuen SW, Cheung CW, et al:: Hand hygiene promotion and the participation of infection control link nurse: an effective innovation to overcome campaign fatigue. Am J Infect Control. 2013; 41(12): 1281-1283. PubMed Abstract | Publisher Full Text

12. Abrams Z, Vee E: Personalized Ad Delivery when Ads Fatigue: An Approximation Algorithm. Proceeding, WINE'07 Proceedings of the 3rd international conference on Internet and network economics. Springer-Verlag Berlin, Heidelberg. 2007; 4858: 535-540. Publisher Full Text

13. Peru, Mexico, and Argentina Help the Region of the Americas Beat the Guinness World Record for Simultaneous Handwashing. Reference Source 


\section{Open Peer Review}

\section{Current Peer Review Status:}

\section{Version 1}

Reviewer Report 10 February 2015

https://doi.org/10.5256/f1000research.5771.r7083

(C) 2015 Holmes A. This is an open access peer review report distributed under the terms of the Creative Commons Attribution License, which permits unrestricted use, distribution, and reproduction in any medium, provided the original work is properly cited.

\section{Alison Holmes \\ Department of Infectious Diseases, Imperial College London, London, UK}

The authors of this study should be praised for approaching the matter of behavioural fatigue from such a refreshing angle. As such, their experience was an innovative activity.

Technically, the paper is well written, although I feel that perhaps the initial sections focusing on evidence regarding hand hygiene campaigns was too long, considering the overall extension of the paper. Likewise, the authors may have been able to benefit related from including some existing evidence from other fields related to overcoming behavioural fatigue.

Whilst the authors indicate that their intervention managed to increase compliance in 2 areas from 10\% in 2012 (mentioned in "...improvement was noted in all the 19 clinical areas except for two where together there was a decline in compliance from 42\% to 10\%") to 95\% in June 2014, it would have been extremely useful to see the decay rate of such boost (I accept that the authors highlight as a limitation of their paper the need to see the longer term impact of their intervention, but I feel that as the problem they tried to solve was related to compliance fatigue, we would have benefited from examining how well their initiative fared).

But these suggestions should not impact on the merit of the paper, which is showcasing an innovative approach focused on maintaining engagement with desired hand hygiene behaviours.

Competing Interests: No competing interests were disclosed.

\section{I confirm that I have read this submission and believe that I have an appropriate level of expertise to confirm that it is of an acceptable scientific standard.}

Author Response 11 Feb 2015

Ben Cowling, The University of Hong Kong, Pokfulam, Hong Kong

Thank you for these comments which we greatly appreciate. We will look into the literature 
on overcoming campaign fatigue in other fields. We agree that examining the medium to longer term compliance is important and we are continuing to monitor $\mathrm{HH}$ compliance in this hospital.

Competing Interests: No competing interests

Reviewer Report 19 January 2015

https://doi.org/10.5256/f1000research.5771.r7084

(C) 2015 Erasmus V. This is an open access peer review report distributed under the terms of the Creative Commons Attribution License, which permits unrestricted use, distribution, and reproduction in any medium, provided the original work is properly cited.

\section{Vicki Erasmus}

Department of Public Health, Erasmus MC University Medical Center Rotterdam, Rotterdam, The Netherlands

This is an interesting intervention study with a good twist on keeping hand hygiene interesting for healthcare professionals. The intervention can also inspire other hospitals to undertake quality improvement which is excellent! In general the paper is well written with a good literature base, and great effort were undertaken to ensure reliability during the record breaking attempt, including two witnesses. I have two reservations though, and hope the authors could add something on these points.

1. The authors report an increased compliance from 50->83\%, although it in unclear how or where this was measured. Was this data collected after the intervention (how long after?) in hospital wards? More details on this could help place the results in perspective and help other professigonal undertake similar efforts.

2. I miss a discussion of the project. By listing some of their limitations others can be helped in further improving similar activities.

Competing Interests: No competing interests were disclosed.

\section{I confirm that I have read this submission and believe that I have an appropriate level of expertise to confirm that it is of an acceptable scientific standard, however I have significant reservations, as outlined above.}

Author Response 11 Feb 2015

Ben Cowling, The University of Hong Kong, Pokfulam, Hong Kong

Thank you for these comments which we greatly appreciate. We have made some minor revisions to our article to address the points made by the reviewer. Specifically, we have now clarified the dates of the Guinness World Record activity and the dates of subsequent 
assessment of $\mathrm{HH}$ compliance, in May 2014 and June 2014 respectively. We have also added a brief discussion of the project and the limitations, which will help others planning similar activities.

Competing Interests: No competing interests

Reviewer Report 06 November 2014

https://doi.org/10.5256/f1000research.5771.r6323

(c) 2014 McLaws M. This is an open access peer review report distributed under the terms of the Creative Commons Attribution License, which permits unrestricted use, distribution, and reproduction in any medium, provided the original work is properly cited.

\section{Mary-Louise McLaws}

School of Public Health and Community Medicine, University of New South Wales, Sydney, NSW, Australia

This manuscript reports on a unique project aimed at refreshing the support for a WHO global hand hygiene compliance program in healthcare workers from a tertiary teaching hospital in Hong Kong. The manuscript is well written and has succinctly reported the literature to highlight the lack of research into methods to amelioration fatigue. The only comment I have to improve on this excellent manuscript is to include a reference about the need for behavioural research (Page 2, paragraph 6), after “.... behavioural determinants is needed" e.g. by Whitby M et al. (2007).

Competing Interests: No competing interests were disclosed.

\section{I confirm that I have read this submission and believe that I have an appropriate level of expertise to confirm that it is of an acceptable scientific standard.}

Author Response 11 Feb 2015

Ben Cowling, The University of Hong Kong, Pokfulam, Hong Kong

Thank you for these comments which we appreciate. We have incorporated the reference suggested by the reviewer in our revised manuscript.

Competing Interests: No competing interests. 
The benefits of publishing with F1000Research:

- Your article is published within days, with no editorial bias

- You can publish traditional articles, null/negative results, case reports, data notes and more

- The peer review process is transparent and collaborative

- Your article is indexed in PubMed after passing peer review

- Dedicated customer support at every stage

For pre-submission enquiries, contact research@f1000.com 